\title{
Impact of Soil Fertility Improving Trees on Crop Productivity and Farmer Wealth in Zambia
}

\author{
Elias Kuntashula ${ }^{1}$ \\ ${ }^{1}$ Agricultural Economics and Extension Department, University of Zambia, Lusaka, Zambia \\ Correspondence: Elias Kuntashula, Agricultural Economics and Extension Department, University of Zambia, P. \\ O. Box 32379, Lusaka, Zambia. Tel: 260-977-748-335. E-mail: ekuntashula@unza.zm
}

\author{
Received: March 15, 2017 Accepted: April 12, 2017 Online Published: May 20, 2017 \\ doi:10.5539/sar.v6n3p14 \\ URL: https://doi.org/10.5539/sar.v6n3p14
}

\begin{abstract}
There has been low uptake of soil fertility improving tree technologies that have been promoted as alternatives to the costly inorganic fertiliser among the poor resource farmers of Sub Saharan Africa. This is surprising given that the majority of smallholder farmers cannot afford inorganic fertilisers. Are these technologies effective? Using data collected in 2013 from 1,231 households across six districts of Zambia, this study showed that the tree technologies increased maize productivity. However, increases in maize productivity were less than those obtained from controlled on-station and field experiments where the technologies could double or more than double maize productivity according to literature. The technologies capacity to marginally contribute to wealth creation was confirmed. Socioeconomic constraints including labour, information access, land and credit need to be tackled for the technologies to give maximum benefits. Research on fertiliser trees should therefore be redirected towards the discovery of such resource constraints saving technologies.
\end{abstract}

Keywords: maize productivity, soil fertility improving trees, wealth index, endogenous switching regression, Zambia

\section{Introduction}

There is increasing recognition that challenges posed by climate change, and the accompanying adaptation measures cannot be delinked from the issues of food security within the agricultural practices sector. Therefore agricultural productivity technologies such as agroforestry that offer multiple roles of food provision and environmental stewardship are increasingly being seen as offering key roles in mitigating climate change. Soil fertility improving tree technologies is an agroforestry product of many years of agroforestry research and development by the World Agroforestry Centre (WAC), and offers an ecologically robust approach to soil fertility improvement in Sub Saharan Africa. It was developed in the 1980s in response to acute poverty and limited use of inorganic fertilizers by most small scale farmers in the region (Mafongoya et al., 2006).

In addition to increasing crop yields, the tree technologies also provide ecosystem services such as carbon sequestration, biodiversity conservation and protection of watershed among others (Sileshi et al., 2007) that help to mitigate climate change effects. The main objective of the promotion of these technologies is to increase private benefits for small scale farmers through improved soil fertility. It is expected that where farmers perceived private benefits, the demand for the technologies would be higher. This expectation is reasonable for Sub Saharan Africa region where the majority of small scale farmers are unable to afford and apply the inorganic fertilizers at recommended rates and at the appropriate time because of high cost and delivery delays (Kwesiga et al., 2003; Akinnifesi et al., 2006). However, there have been low levels of the soil fertility tree technologies' adoption among the small scale farmers in the region (Akinnifesi et al., 2006; Ajayi et al., 2007). To what extent do the tree technologies improve small scale farmers' private benefits? The objective of this study was to estimate the private benefits in terms of crop yields and asset accumulation that small scale farmers obtain as a result of soil fertility improving trees' adoption.

The adoption of the tree technologies may be influenced by a variety of factors including climate conditions, household and farm characteristics, and attributes of the technology itself (Ajayi et al., 2007) as well as the policy environment. All these important factors are linked to the benefits that the farmer would get from the technologies. Secondly, the generation of environmental services by the technologies, noted earlier, is never reflected in these benefits, thus without government involvement in providing greater incentives, the level of 
private investment in the technology could be less than socially optimal. Thus, in this later case the low adoption levels could be reflecting this fact. Given the multiple roles, these tree technologies fit well in serving the seemingly polarizing roles of food and environmental service provisioning. Recent increases in climate change and general unpredictability of agricultural operations, puts tree based technologies at the core of sustainable agricultural development. Sustainable agricultural development is widely acknowledged as an important component in a strategy to respond to the twin challenges of poverty and environmental degradation and adaptation to climate change (Antle \& Diagana, 2003).

Soil fertility improving trees uses natural resource management principles to replenish soil fertility. The practice involves planting fast growing nitrogen-fixing leguminous trees and shrubs which produce large quantities of biomass that easily decomposes and release nitrogen for crop growth (Kwesiga \& Coe, 1994). Through nutrient recycling principles, the trees capture atmospheric nitrogen and release it into the soil upon decomposition and subsequently nourish crops for the next 2-3 planting seasons in the case of maize, the staple food in most parts of Sub-Saharan Africa. The main species used as soil fertility improving tree technologies include; Gliricidia sepium (Mexican lilac), Cajanus cajan (Pigeon pea), Sesbania sesban (River bean), Tephrosia vogelii (Fish bean) and Faidherbia albida (Winter thorn).

Biophysical experiments on soil fertility improving trees show increases of maize yield of about two times that obtained from resource poor small scale farmers' de facto practice in which maize is cultivated continuously without external fertilization (Kwesiga et al., 2003, Akinnifesi et al., 2006). Socioeconomic quasi-experiments on-farm to evaluate the technologies efficacy on farmers' fields have rarely been done and analysed. A few studies (Quinton et al., 2010; Kuntashula \& Mungatana, 2013) managed to incorporate the socioeconomic characteristics of small scale farmers in evaluating impact of these technologies on farmer welfare. Quinion et al (2010) used Sign and Signed Rank Non-parametric analysis to test for a change in the crop yield and asset variables between pre- and post-adoption in two districts of Malawi. This analysis failed to impose proper counter factual analyses that could have solely attributed the increases in several outcome variables to the technologies. For instance the possibility of unobserved differences between the adopting and non-adopting farmers was not taken into consideration. In attempting to improve on the impact estimation, Kuntashula and Mungatana (2013) invoked counter factual analysis, and used matching and endogenous switching regression to account for both observed and unobserved differences between the adopters and non-adopters of the technologies. However, the study assessed impact on only three agroforestry catchment areas in one district of Zambia hence compromising on issues of generalization. In addition, lack of using instrumental variables in controlling for unobservable differences when using the endogenous switching regression model in Kuntashula and Mungatana (2013) renders the findings less robust.

Moreover, both Quinton et al (2010) and, Kuntashula and Mungatana (2013), did not tackle more holistically the issue of asset creation as a result of adopting the tree technologies. Kuntashula and Mungatana (2013) did not test whether adopting the technologies increased farmer asset levels while Quinton et al (2010) estimated differences in individual asset levels between adopters and non-adopters. The use of differences in individual asset levels could provide misleading results. The welfare statuses of farmers depend on varying levels of different assets they possess. Since these assets contribute differently to households' wealth status, normalizing them to avoid distortions due to different measurement scales becomes necessary. Once normalized, indices can then be constructed and aggregated to facilitate ranking (Langyintuo \& Mungoma, 2008). We argue in this study that what happens to the overall asset wealth index when a farmer adopts these technologies could provide a better measure of impact on farmer wealth creation. We thus, as a contribution to literature, calculate the overall wealth index from the varying levels of individual assets of the farmers and subject this index to impact evaluation that controls for other differences between the adopters and non-adopters of the technologies. This is in addition to imposing proper counter factual analyses on the ability of the technologies to increase maize productivity. The study confirms that improved tree fallows increases maize productivity and wealth levels of small scale farmers. The predicted increases in both maize productivity and wealthy levels are however constrained by various socioeconomic factors. The rest of the paper is structured as follows: data sources immediately follow this introduction. Then we give the theoretical frameworks on the calculation of the wealth index, matching strategies and endogenous switching models. This is followed by the results and discussion sections. Finally conclusions are drawn based on the findings of the study.

\section{Methodology}

\subsection{Data sources}

The data used in this paper came from a Climate Change Supplemental Survey carried out in 2013 on a sample of 
1,231 households in six selected districts of Zambia. The six districts were Choma and Sinazongwe in the Southern region, Nyimba and Petauke in the Eastern region, and Mpika and Serenje in the Northern region of the country (Figure 1). The data was collected under the auspices of the University of Zambia (UNZA) Climate Change and Land Use project funded by Michigan State University. The participating households in the six districts were those who had participated in a nationally representative cross sectional 2012 Rural Agricultural Livelihoods Survey (RALS12) conducted by the Zambia's Central Statistical Office (CSO) and the Indaba Agricultural Policy Research Institute (IAPRI). For the nationally representative sample CSO draws the sample from all the districts in Zambia. For sampling purposes, the CSO subdivides each ward in Census Supervisory Areas (CSA) and Standard Enumeration Areas (SEAs). Each SEA contains between $100-150$ households. A total sample of 680 CSAs is allocated nationally to each province and district proportional to its size in terms of households. About 20 households are randomly selected from each of the 680 SEAs in the sample (RALS12 Sampling Manual).

The Climate Change and Land use project data collection process involved the administration of a semi structured questionnaire in the six districts on climate change related issues. The broad issues covered in this survey included; smallholder farmers' perceptions about climate change, mitigation and adaption against climate change disasters, yields and incomes from entrepreneurial and agricultural activities in the previous farming season (2012/13 season).

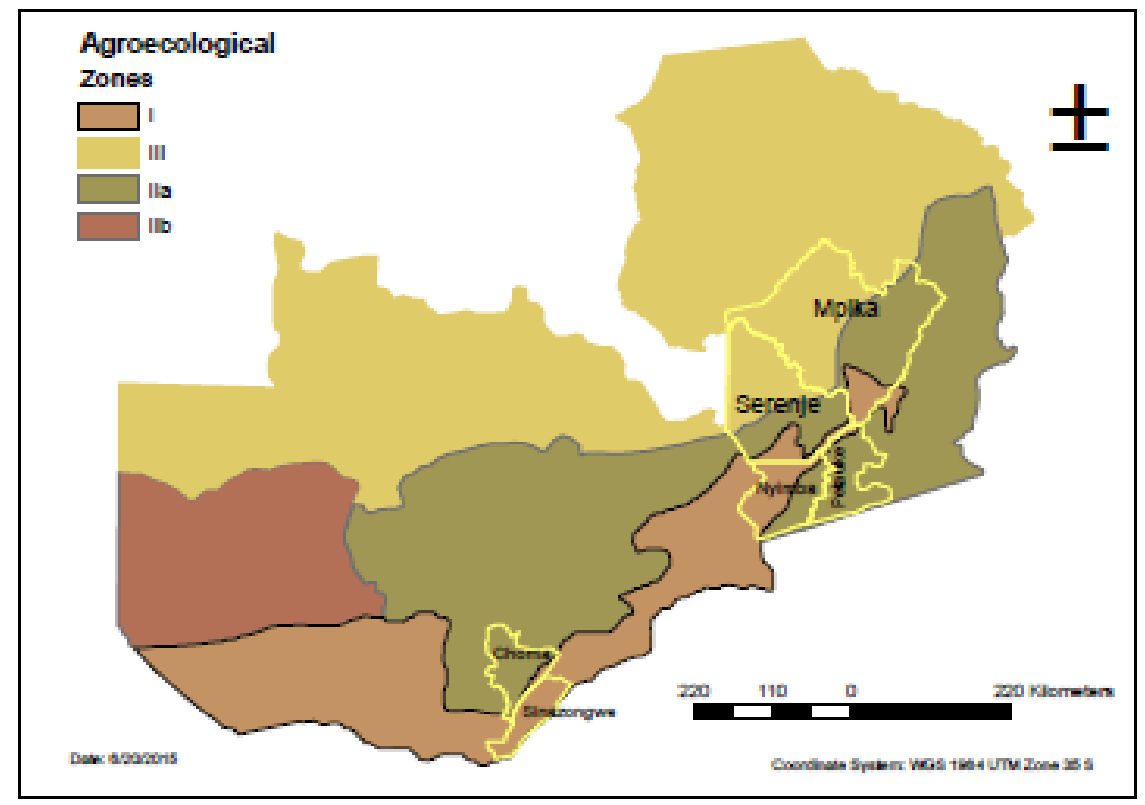

Figure 1. Location of the study sites in Zambia

Source: Chabala et al. (2015)

\subsection{Estimating the Household Wealth Index}

Borrowing from Langyintuo and Mungoma (2008), we postulated that welfare status of households depended on varying levels of different assets they possess. Recognizing the fact that these assets contribute differently to households' wealth status, normalizing them to avoid distortions due to different measurement scales becomes necessary. The assets are normalized using equation 1 as follows:

$$
i=\frac{x_{l}-x_{\min }}{x_{\max }-x_{\min }}
$$

where $i$ is the index, $\mathrm{x}_{1}$ is the level, while $\mathrm{x}_{\min }$ and $\mathrm{x}_{\max }$ are the minimum and maximum values of $\mathrm{x}$, respectively taken from the actual data collected.

The normalized indices can be aggregated using some Principal Component Approaches (PCA) and equation 2, to come up with a composite index for each household (Filmer \& Pritchett, 1998; Langyintuo, 2008; Kuntashula et al., 2014). 


$$
W_{j}=\sum_{i=1}^{k}\left[b_{i}\left(a_{j i}-x_{i}\right)\right] / s_{i}
$$

where: $\boldsymbol{W}_{\boldsymbol{j}}$ is a standardized wealth index for each household; $\mathbf{b}_{\boldsymbol{i}}$ represents the weights (scores) assigned to the $(k$ ) variables on the first principal component; $\mathbf{a}_{j i}$ is the value of each household on each of the $k$ variables; $\mathbf{x}_{i}$ is the mean of each of the $k$ variables; and $\mathbf{s}_{i}$ the standard deviations.

This index facilitates the ranking in terms of wealth of a household relative to others in the sample under study. A negative index means that, relative to the communities' measure of wealth, the household is poorly endowed and hence worse-off while a positive index signifies that the household is well-off. A zero value, which is also the sample mean index, implies the household is neither well-off nor worse-off. The steps used to compute the wealth index are provided in Langyintuo (2008).

\subsection{Estimating Impact of Soil Fertility Improving Tree Fallows}

The main challenge of estimating impact of soil fertility improving tree technologies on either maize productivity or wealth status of households is to determine what would have happened to the adopters if they had not adopted. That is, we need to determine maize productivity or wealth index of the households in the absence of adoption. The household's outcome in the absence of adoption would be its counterfactual. The problem here is that while adoption's impact (independent of other factors) can truly be assessed only by comparing actual and counterfactual outcomes, the counterfactual is not observed. Therefore creating a convincing comparison group for the adopters in light of this missing data becomes of paramount importance.

\subsubsection{Creating a Counter-Factual Using the Propensity Score Matching}

Propensity score matching (PSM) involves constructing a comparison group that is based on a model of the probability of participating in the adoption process, using observed characteristics. In PSM, each adopter is matched to a non-adopter on the basis of this single propensity score, which reflects the probability of adopting conditional on their different observed characteristics X (Rosenbaum \& Rubin, 1983). The average treatment effect on the treated (ATT) of the technology is then calculated as the mean difference in outcomes across these two groups. Letting $Y_{1}$ and $Y_{0}$ to be the outcomes of the adopters and non-adopters respectively, ATT entails:

$$
E\left(Y_{1}-Y_{0} \backslash T=1\right)
$$

where; $E$ is the expectation in the difference in the outcome $\left(Y_{1}-Y_{0}\right)$ between adopting the technology, $T=1$ and the counter factual outcome if adoption had not been embraced $T=0$.

For PSM to be valid, there should be imposition of the Conditional Independent Assumption (CIA) that states that, given a set of observable covariates $X$, the potential outcome in case of no treatment or not adopting is independent of technology assignment:

$$
Y_{0} \amalg T \backslash(X)
$$

The second condition is the overlap condition, which ensures that for each adopting household there are non-adopting households with the same observables. With the above two conditions, within each cell defined by $X$, technology adoption assignment is random, and the outcome of control households can be used to estimate the counter factual outcome of the treated in the case of no treatment.

The propensity scores for this study were estimated using probit regression. Independent variables included in the PSM estimation were those which were either correlated with both the outcome and treatment or only correlated with the outcome and not the treatment variable (Brookhart et al., 2006). Various models were specified until the most complete and robust specification that satisfied the balancing tests and establishment of the common support region was obtained.

Different techniques can be used to implement matching on the basis of the propensity score. These include nearest-neighbour $(\mathrm{NN})$ matching, caliper and radius matching, stratification and interval matching, and kernel matching and local linear matching (LLM). The pros and cons of these matching algorithms can be reviewed in Caliendo and Kopeinig (2008). In this study, we chose two matching algorithms, nearest neighbour and kernel matching that gave a trade-off between matching quality and efficiency of the estimators (Caliendo \& Kopeinig, 2008).

\subsubsection{Creating the Counter-Factual Using the Endogenous Switching Model}

Even if we account for all observables, there can be a situation where the unobservable factors between the 
adopters and non-adopters can be different. In regression, unobservable factors are reflected in the error term. Since the independent variables can simultaneously affect the outcome variables .i.e. maize productivity and wealth index, and the treatment variable, then the error term in the explicit outcome regression we are attempting to estimate may be related to the error term in the implicit adoption or treatment model. To account for possible endogeneity bias, the study employed endogenous switching regression (ESR) techniques.

ESR model is comprised of the selection equation and two continuous regressions that describes the behaviour of the farmer as he faces the two regimes of adopting the technologies or not. The selection equation is defined as;

$$
I_{i}^{*}=\beta X_{i}+\alpha Z_{i}+\mu_{i} \quad \text { with } I_{i}= \begin{cases}1 & \text { if } I_{i}^{*}>1 \\ 0 & \text { otherwise }\end{cases}
$$

where $I_{i}^{*}$ is the unobservable variable for technology adoption and $I_{i}$ is its observable counterpart which is the dependent variable which equals one, if the farmer has adopted and zero otherwise. $\beta$ and $\alpha$ are vectors of parameters while $X_{\mathrm{i}}$ are vectors of exogenous variables also included in output equations 6 and 7. $Z_{i}$ are non-stochastic vectors of variables that explain only the selection process and have no direct effect on the outcome. These variables also referred to as instruments are very important for identification purposes. The household marital status variable was significantly correlated with adoption of tree technologies but did not have any direct effect on maize yields. Climate change awareness was also significantly correlated with the technologies but was not correlated with the wealth index. These two variables were therefore found to be suitable instruments and were used in identifying the effects of the technologies on maize productivity and household wealth index. $\mu_{i}$ is random disturbances associated with the adoption of the technologies.

The two outcome regression equations where farmers face the regimes of adopting or not to adopt are defined as follows:

$$
\begin{array}{ll}
\text { Regime 1: } y_{1 i}=\beta_{1} X_{1 i}+\varepsilon_{1 i} & \text { if } I_{i}=1 \\
\text { Regime 2: } y_{2 i}=\beta_{2} X_{2 i}+\varepsilon_{2 i} & \text { if } I_{i}=0
\end{array}
$$

where $Y_{j i}$ are the outcome variables (maize yield or wealth index) in the continuous equations; $\beta_{1}$ and $\beta_{2}$ are vectors of parameters; and $\varepsilon_{1 i}$ and $\varepsilon_{2 i}$ are random disturbance terms. The assumptions on the error terms, their variance, covariances, and their expected values can be reviewed in Maddala and Nelson (1975), and/or Kuntashula and Mungatana (2013). According to Lokshin and Sajaia (2004) the selection equation and the outcome regression equations can simultaneously be estimated using the full information maximum likelihood (FIML) estimation. Upon estimation, the endogenous switching regression model can be used to compare the various conditional expected outcomes of the farm households. These include:

(a) Maize yield (wealth index) for households that adopted

(b) Maize yield (wealth index) for households that did not adopt

(c) Maize yield (wealth index) for households who adopted had they not adopt

(d) Maize (wealth index) for non-adopting households had they adopted.

Cases (a) and (b) represent the actual expectations observed in the sample while cases (c) and (d) represent the counterfactual expected outcomes. The effect of the treatment on the treated (TT) (effect of improved tree fallows on the adopters) is the difference between (a) and (c) while the effect of the treatment on the untreated (TU) for the farm households that actually did not adopt improved tree fallows is the difference between (d) and (b).

Heterogeneity effects due to unobservable factors such as management skills can be obtained by calculating the difference in the expected outcomes of the adopters of improved tree fallows (a) and that of the non-adopters had they adopted (d). Similarly for the group of farm households that decided not to adopt, the difference between (c) that the adopters did not adopt and (b) the non-adopters can be calculated.

Finally, "transitional heterogeneity" (TH), estimating whether the effect of adopting improved trees fallows is larger or smaller for the households that actually adopted the technologies or for the household that actually did not adopt in the counterfactual case that they did adopt, is computed by getting the difference between TT and TU. 


\section{Results and Discussions}

\subsection{Descriptive Statistics}

The variables used in the various estimation models are shown in Table 1. The descriptive statistics of the sample are shown in Table 2. The average age of the household head was around 46 years. There were no statistical differences between the age of the adopters and the non-adopters of soil fertility improving tree technologies. The sample was dominated by male headed households. More adopters than the non-adopting households were headed by males. Close to three quarters of the sample was monogamously married with more adopters being monogamously married than their non-adopting counter parts. The adopters had more farm land size and cropped land areas than the non-adopters. More adopters had received conservation farming advice, had used draught power and had access to both information and credit.

In terms of the outcomes variables, the adopters had an average higher wealth index, higher maize yields per hectare and higher total household maize yields than the non-adopting households.

Table 1. Variables used in Various Estimation Models

\begin{tabular}{lll}
\hline Variable & Definition & Units or codes \\
\hline Age & Age of household head & Years \\
Sex & Gender of household head & 1 if male, 0 otherwise \\
Monmarried & Household head is monogamously married & 1 if monogamously married, 0 otherwise \\
Educ & Level of education of household head & 1 = primary, 2= secondary, $3=$ tertiary \\
Hsize & Household members & Number of members \\
Farmsize & Size of farm & Number in hectares \\
Croparea & Cropped area & Number in hectares \\
CFadvise & Receiving conservation farming advise & 1 if household received advise, 0 otherwise \\
Labhire & Household hiring labour & 1 if hired labour, 0 otherwise \\
AnimLab & Household using animal labour & 1 if used animal labour, 0 otherwise \\
AccessC & Household accessing credit & 1 if accessed credit, 0 otherwise \\
InforAcc & Household accessing agricultural extension & 1 if accessed extension, 0 otherwise \\
MGroup & Household belonging to agricultural group & 1 if member belongs to group, o otherwise \\
Windex & Household wealth index & Index computed following Langyintuo (2008) \\
Mzha ${ }^{-1}$ & Maize yield per unit area & Tones per hectare \\
Totmz & Household total maize yield & Tones \\
\hline
\end{tabular}

Table 2. Descriptive Statistics of the Sample

\begin{tabular}{llll}
\hline Variable & Over all & Non-Adopters & Adopters \\
\hline Age & $46.28(0.427)$ & $46.35(0.458)$ & $45.85(1.187)$ \\
Sex & $0.80(0.011)$ & $0.79(0.012)$ & $0.89(0.025)^{* * *}$ \\
Monmarried & $0.74(0.013)$ & $0.73(0.013)$ & $0.80(0.032)^{*}$ \\
Educ & $1.18(0.019)$ & $1.16(0.021)$ & $1.30(0.054)$ \\
Hsize & $6.08(0.069)$ & $6.09(0.074)$ & $6.02(0.193)$ \\
Farmsize & $2.97(0.103)$ & $2.87(0.111)$ & $3.64(0.267)^{* *}$ \\
Croparea & $1.67(0.053)$ & $1.59(0.056)$ & $2.18(0.160)^{* * *}$ \\
CFadvise & $0.63(0.014)$ & $0.62(0.015)$ & $0.69(0.037)^{*}$ \\
Labhire & $0.17(0.011)$ & $0.17(0.011)$ & $0.21(0.033)$ \\
AnimLab & $0.35(0.014)$ & $0.34(0.014)$ & $0.44(0.039)^{* *}$ \\
AccessC & $0.14(0.009)$ & $0.13(0.010)$ & $0.19(0.031)^{*}$ \\
InforAcc & $0.89(0.009)$ & $0.88(0.010)$ & $0.93(0.021)^{*}$ \\
MGroup & $0.45(0.014)$ & $0.43(0.015)$ & $0.59(0.040)^{* * *}$ \\
Windex & $-4.06 \mathrm{e}-12(0.028)$ & $-0.07(0.029)$ & $0.50(0.097)^{* * *}$ \\
Mzha ${ }^{-1}$ & $2.20(0.051)$ & $2.10(0.053)$ & $2.83(0.155)^{* * *}$ \\
Totmz & $3.49(0.161)$ & $3.13(0.163)$ & $5.77(0.533)^{* * *}$ \\
\hline
\end{tabular}

\subsection{Propensity Score Estimates of the Impact of Soil Fertility Improving Tree Technologies on Maize Productivity}

Both matching algorithms used showed that the technologies increase maize productivity (Table 3). Using the NNM, the technologies were found to increase maize productivity by $21 \%$ while use of KM showed that the 
technologies would increase maize productivity by $18 \%$. The NNM gives a high quality matching estimator than the KM since only those control households whose propensity scores are close (near neighbour) to the treated households' propensity scores are used in the matching. The results indicate that only 132 non-adopting (control) households were used in the estimation of the ATT using NNM algorithm. In contrast 967 non-adopting households were used when using the KM algorithm. There is however a trade off in terms of efficiency of the estimators in that the reduced number of control units in the case of NNM leads to increases in the standard errors. Again this is shown in the results since the standard error from NNM was higher than that from KM. Generally however the technology has the capacity to increase maize production per hectare.

Table 3. ATT Estimation of Maize Productivity using Nearest Neighbour and Kernel Matching Methods

\begin{tabular}{llllll}
\hline Method & Number treated & Number Control & $\begin{array}{l}\text { Average Treatment } \\
\text { on Treated (ATT) }\end{array}$ & $\begin{array}{l}\text { Bootstrapped } \\
\text { Standard Error }\end{array}$ & t value \\
\hline Nearest Neighbour & 152 & 132 & 0.213 & 0.056 & 3.779 \\
Kernel Matching & 152 & 967 & 0.181 & 0.043 & 4.247 \\
\hline
\end{tabular}

\subsection{Propensity Score Estimates of the Impact of Soil Fertility Improving Tree Technologies on the Wealth Index}

Both the NNM and KM approaches showed that the soil fertility improving tree technologies had the capacity to increase household wealth. The scale of wealth increases from the two approaches was similar. The NNM attributed an index of around 0.21 to adoption of the improved tree fallows while the KM showed that the technologies can improve wealth status of a household to an index of 0.22 (Table 4).

Table 4. ATT Estimation of Wealth Index using Nearest Neighbour and Kernel Matching Methods

\begin{tabular}{llllll}
\hline Method & Number treated & Number Control & $\begin{array}{l}\text { Average Treatment } \\
\text { on Treated (ATT) }\end{array}$ & $\begin{array}{l}\text { Bootstrapped } \\
\text { Standard Error }\end{array}$ & t value \\
\hline Nearest Neighbour & 152 & 132 & 0.207 & 0.116 & 1.782 \\
Kernel Matching & 152 & 967 & 0.221 & 0.070 & 3.155 \\
\hline
\end{tabular}

\subsection{Matching Balancing Tests}

Matching was successful as shown by the proportional bias reduction in Table 5. All the variables used in the matching no longer showed significant differences after the matching. The overall matching test also showed that matching was successful. 
Table 5. Matching Balancing Tests

\begin{tabular}{|c|c|c|c|c|c|c|c|}
\hline & & \multicolumn{3}{|l|}{ Mean } & \multirow{2}{*}{$\%$ reduction IbiasI } & \multicolumn{2}{|l|}{ t-test } \\
\hline & & Treated & Control & $\%$ bias & & $\mathrm{T}$ & $p>t$ \\
\hline \multirow[t]{2}{*}{ Logage } & Unmatched & 3.800 & 3.809 & -2.8 & & -0.330 & 0.743 \\
\hline & Matched & 3.800 & 3.813 & -4.2 & -47.3 & -0.380 & 0.708 \\
\hline \multirow[t]{2}{*}{ Sex } & Unmatched & 0.897 & 0.791 & 29.4 & & 3.120 & 0.002 \\
\hline & Matched & 0.897 & 0.893 & 1.1 & 96.3 & 0.110 & 0.981 \\
\hline \multirow[t]{2}{*}{ MonMarried } & Unmatched & 0.800 & 0.729 & 16.6 & & 1.870 & 0.062 \\
\hline & Matched & 0.800 & 0.799 & 0.3 & 98.4 & 0.020 & 0.981 \\
\hline \multirow[t]{2}{*}{ Educ } & Unmatched & 1.297 & 1.164 & 19.6 & & 2.270 & 0.024 \\
\hline & Matched & 1.297 & 1.290 & 1.0 & 95.0 & 0.080 & 0.932 \\
\hline \multirow[t]{2}{*}{ Hsize } & Unmatched & 6.019 & 6.091 & -3.0 & & -0.340 & 0.730 \\
\hline & Matched & 6.019 & 6.005 & 0.6 & 80.2 & 0.050 & 0.959 \\
\hline \multirow[t]{2}{*}{ Ha-plant } & Unmatched & 2.181 & 1.593 & 31.6 & & 3.800 & 0.000 \\
\hline & Matched & 2.181 & 2.242 & -3.2 & 89.8 & -0.240 & 0.814 \\
\hline \multirow[t]{2}{*}{ CFadvise } & Unmatched & 0.690 & 0.616 & 15.7 & & 1.790 & 0.073 \\
\hline & Matched & 0.690 & 0.689 & 0.1 & 99.5 & 0.010 & 0.994 \\
\hline \multirow[t]{2}{*}{ Labhire } & Unmatched & 0.206 & 0.169 & 9.5 & & 1.150 & 0.252 \\
\hline & Matched & 0.206 & 0.203 & 0.9 & 90.3 & 0.080 & 0.938 \\
\hline \multirow[t]{2}{*}{ AnimLab } & Unmatched & 0.439 & 0.337 & 20.9 & & 2.480 & 0.013 \\
\hline & Matched & 0.439 & 0.443 & -0.8 & 96.0 & -0.070 & 0.944 \\
\hline \multirow[t]{2}{*}{ AccessC } & Unmatched & 0.187 & 0.135 & 14.3 & & 1.750 & 0.080 \\
\hline & Matched & 0.187 & 0.186 & 0.3 & 98.1 & 0.020 & 0.983 \\
\hline \multirow[t]{2}{*}{ InforAcc } & Unmatched & 0.929 & 0.881 & 16.4 & & 1.770 & 0.078 \\
\hline & Matched & 0.929 & 0.937 & -2.6 & 84.1 & -0.270 & 0.790 \\
\hline \multirow[t]{2}{*}{ Mgroup } & Unmatched & 0.593 & 0.432 & 32.7 & & 3.790 & 0.000 \\
\hline & Matched & 0.593 & 0.601 & -1.5 & 95.4 & -0.130 & 0.895 \\
\hline \multirow[t]{2}{*}{ Southern } & Unmatched & 0.277 & 0.213 & 15.0 & & 1.810 & 0.070 \\
\hline & Matched & 0.277 & 0.276 & 0.4 & 97.6 & 0.030 & 0.976 \\
\hline \multirow[t]{2}{*}{ Eastern } & Unmatched & 0.510 & 0.481 & 5.6 & & 0.660 & 0.511 \\
\hline & Matched & 0.510 & 0.519 & -2.0 & 64.0 & -0.180 & 0.859 \\
\hline \multirow[t]{3}{*}{ Sample } & & Pseudo R2 & $\begin{array}{l}\text { LR } \\
\text { chi2 }\end{array}$ & $\mathrm{P}>\mathrm{chi} 2$ & Meanbias & Medbias & \\
\hline & Raw & 0.041 & 36.21 & 0.001 & 16.7 & 16.0 & \\
\hline & Matched & 0.000 & 0.20 & 1.00 & 1.4 & 1.0 & \\
\hline
\end{tabular}

3.5 Endogenous Switching Regression Estimates of the Impact of Soil Fertility Improving Tree Technologies on Maize Productivity

The results from the ESR model showed that the maize productivity outcome models for adopters and non-adopters were independently determined (rho close to one, Table 6). The factors influencing maize productivity among the adopters included hiring of labour by the household, using animal draught power and household members belonging to agricultural groups. All these factors positively contributed to household maize productivity (Table 6). For the non-adopters of soil fertility improving trees, the significant factors positively influencing maize productivity included; household member size, hiring of labour, using of animal draught power, access to credit, access to information, belonging to an agricultural group and distance to the town centre (Table 6).

The decision for a household to switch to embracing the soil fertility improving tree technologies was positively significantly influenced by whether the household was headed by males and household members belonging to an agricultural group (Table 6). 
Table 6. Factors Affecting Maize Productivity among Adopters and Non-adopters of Soil Fertility Improving Tree Technologies

\begin{tabular}{lllllll}
\hline & \multicolumn{4}{l}{ Adopters outcome model } & Non-adopters outcome model & Selection model \\
\cline { 2 - 7 } Variables & Coefficient & $\mathrm{Z}$ & Coefficient & $\mathrm{Z}$ & Coefficient & $\mathrm{Z}$ \\
\hline Age & $0.0002(0.0028)$ & 0.08 & $-0.0003(0.001)$ & -0.31 & $-0.0003(0.0032)$ & -0.09 \\
Sex & $0.14(0.129)$ & 1.10 & $0.033(0.0358)$ & 0.93 & $0.44(0.202)$ & 2.18 \\
Educ & $0.11(0.067)$ & 1.63 & $-0.002(0.0214)$ & -0.09 & $0.098(0.0743)$ & 1.32 \\
LogHsize & $0.012(0.116)$ & 0.10 & $0.072(0.0397)$ & 1.82 & $-0.13(0.134)$ & -0.96 \\
Farmsize & $-0.006(0.0135)$ & -0.48 & $-0.007(0.0046)$ & -1.46 & $0.016(0.0148)$ & 1.10 \\
CFadvice & $0.0011(0.095)$ & 0.01 & $0.043(0.0296)$ & 1.45 & $0.027(0.104)$ & 0.26 \\
LabHire & $0.27(0.106)$ & 2.55 & $0.083(0.0366)$ & 2.26 & $0.11(0.119)$ & 0.94 \\
AnimLab & $0.25(0.099)$ & 2.51 & $0.16(0.0328)$ & 4.74 & $0.13(0.110)$ & 1.22 \\
AccessC & $-0.086(0.114)$ & -0.76 & $0.13(0.0413)$ & 3.19 & $0.082(0.131)$ & 0.62 \\
InforAcc & $0.21(0.168)$ & 1.27 & $0.11(0.0451)$ & 2.46 & $0.17(0.173)$ & 0.97 \\
Mgroup & $0.20(0.091)$ & 2.19 & $0.17(0.0300)$ & 5.52 & $0.25(0.101)$ & 2.51 \\
Bomadist & $0.0003(0.0016)$ & 0.21 & $0.001(0.001)$ & 1.78 & $-0.002(0.0019)$ & -0.85 \\
Southern & $-0.41(0.139)$ & -2.91 & $-0.44(0.0460)$ & -9.66 & $0.26(0.158)$ & 1.67 \\
Eastern & $-0.159(0.129)$ & -1.18 & $-0.36(0.0383)$ & -9.30 & $0.11(0.142)$ & 0.76 \\
Mstatus & & & & & $0.036(0.065)$ & 0.55 \\
Constant & $-0.35(0.411)$ & -0.84 & $1.05(0.117)$ & 9.01 & $-1.95(0.491)$ & -3.96 \\
Rho & $0.93(0.0404)$ & & $-0.71(0.091)$ & & & \\
LR test of independence of equations: chi2 $(1)=11.49$ & Prob > chi2 $=0.0007$ & \\
\hline
\end{tabular}

Dependent variable: Log Maize yield per hectare 2012/2013

Standard errors in parentheses

According to estimates from ESR model, adopting of soil fertility improving tree technologies increased maize productivity by $75 \%$. Had the non-adopters decided to adopt the technology their maize yields per hectare could have doubled (Table 7). The adopters would get more yields per unit area for adopting than the non-adopters if they had adopted, but the adopters would still be better off than the non-adopters in the situation of both groups not adopting (Table 7).

Table 7. Effects of Soil Improving Tree Technologies on Log of Maize Productivity

\begin{tabular}{|c|c|c|c|}
\hline & \multicolumn{2}{|l|}{ Decision Stage } & Treatment effect \\
\hline & Adopted & Not to adopt & Difference (TT or TU) \\
\hline Adopters $(\mathrm{N}=155)$ & $1.24(0.0178)$ & $0.48(0.0189)$ & $0.752(0.0171)^{* * *}$ \\
\hline Non-adopters $(\mathrm{N}=1036)$ & $1.02(0.0066)$ & $-0.003(0.0072)$ & $1.023(0.0042)^{* * * *}$ \\
\hline Heterogeneity effects & $\mathrm{BH}_{1}=0.22$ & $\mathrm{BH}_{2}=0.483$ & $\mathrm{TH}=-0.271$ \\
\hline
\end{tabular}

$\mathrm{TT}=$ treatment effect on the treated (adopting - had not adopted), TU = treatment effect on the untreated (had they adopted - not adopted), $\mathrm{BH}=$ Base heterogeneity (adopted - had they adopted), TH = Transitory heterogeneity $(\mathrm{TT}-\mathrm{TU})$

\subsection{Endogenous Switching Regression Estimates of the Impact of Soil Fertility Improving Tree Technologies on Wealth Index}

The results from ESR model showed that the wealth index outcome models for adopters was jointly determined with the selection or adopting decision model. However the outcome model for the non-adopters was independently determined (Table 8). Factors that significantly contributed to improving the wealth status of the adopters included: age of the household head, education level, cropped area, access to credit, group membership and distance to town. The wealth status of the non-adopters was enhanced by the household being male headed, education level of the household head, cropped area, whether the head had received conservation advice, hiring of labour, using animal draught power, access to credit, access to information, group membership and distance to town.

Switching to planting the tree technologies was positively affected by access to information and credit and negatively affected by cropped area (Table 8). 
Table 8. Factors Affecting Wealth Index among Adopters and Non-adopters of Soil Fertility Improving Tree Technologies

\begin{tabular}{lllllll}
\hline & \multicolumn{4}{l}{ Adopters outcome model } & Non-adopters outcome model & Selection model \\
\cline { 2 - 7 } Variables & Coefficient & $\mathrm{Z}$ & Coefficient & $\mathrm{Z}$ & Coefficient & $\mathrm{Z}$ \\
\hline Age & $0.009(0.0046)$ & 1.94 & $0.002(0.00165)$ & 1.48 & $-0.002(0.0026)$ & -0.93 \\
Sex & $0.16(0.217)$ & 0.75 & $0.25(0.061)$ & 4.13 & $0.004(0.115)$ & 0.21 \\
Educ & $0.23(0.105)$ & 2.17 & $0.066(0.036)$ & 1.82 & $0.012(0.058)$ & 0.21 \\
LogHsize & $-0.071(0.179)$ & -0.40 & $0.049(0.067)$ & 0.73 & $-0.002(0.110)$ & -0.01 \\
CropArea & $0.353(0.051)$ & 6.85 & $0.25(0.144)$ & 17.10 & $-0.10(0.024)$ & -4.01 \\
CFadvice & $-0.066(0.159)$ & -0.42 & $0.088(0.050)$ & 1.74 & $-0.081(0.083)$ & -0.97 \\
LabHire & $0.067(0.179)$ & 0.37 & $0.31(0.063)$ & 4.87 & $-0.13(0.102)$ & -1.24 \\
AnimLab & $0.19(0.156)$ & 1.22 & $0.19(0.055)$ & 3.57 & $-0.018(0.088)$ & -0.21 \\
AccessC & $0.62(0.194)$ & 3.21 & $0.30(0.068)$ & 4.42 & $0.24(0.106)$ & 2.28 \\
InforAcc & $0.20(0.456)$ & 0.45 & $0.24(0.079)$ & 3.02 & $0.89(0.278)$ & 3.21 \\
Mgroup & $0.36(0.143)$ & 2.52 & $0.42(0.051)$ & 8.36 & $0.018(0.087)$ & 0.20 \\
Bomadist & $0.006(0.0026)$ & 2.36 & $0.002(0.0009)$ & 1.66 & $0.0002(0.0015)$ & 0.16 \\
Southern & $0.13(0.224)$ & 0.56 & $0.092(0.079)$ & 1.16 & $0.092(0.131)$ & 0.70 \\
Eastern & $-0.37(0.225)$ & -1.64 & $0.034(0.069)$ & 0.50 & $0.18(0.120)$ & 1.48 \\
CCaware & & & & & $0.069(0.073)$ & 0.95 \\
Constant & $-1.46(1.074)$ & -1.36 & $-1.79(0.201)$ & & $-1.61(0.401)$ & -4.01 \\
Rho & $-0.11(0.606)$ & & $-0.99(0.0044)$ & & & \\
LR test of independence of equations: chi2 $(1)=74.40$ & Prob > chi2 =0.0000 & \\
\hline
\end{tabular}

Dependent variable: Wealth index 2012/2013

Standard errors in parentheses

By adopting the tree technologies, the adopters moved from being in the poor category had they not adopted to the well-endowed category. Although the non-adopters were marginally well off, they would have improved tremendously in their wealth status, had they adopted the technologies (Table 9).

Table 9. Effects of Soil Fertility Improving Tree Technologies on Household Wealthy Index

\begin{tabular}{clll}
\hline \multicolumn{3}{c}{ Decision Stage } & Treatment effect \\
\cline { 2 - 4 } & Adopted & Not to adopt & Difference (TT or TU) \\
Adopters $(\mathrm{N}=151)$ & $0.52(0.076)$ & $-1.041(0.052)$ & $1.56(0.036)^{* * *}$ \\
Non-adopters $(\mathrm{N}=958)$ & $0.30(0.027)$ & $0.023(0.019)$ & $0.28(0.013)^{* * *}$ \\
Heterogeneity effects & $\mathrm{BH}_{1}=0.22$ & $\mathrm{BH}_{2}=-1.064$ & $\mathrm{TH}=1.28$ \\
\cline { 2 - 4 }$* * 0<<01, * * \mathrm{p}<0.05, * \mathrm{p}<0.1$ & & &
\end{tabular}

$\mathrm{TT}=$ treatment effect on the treated (adopting - had not adopted), $\mathrm{TU}=$ treatment effect on the untreated (had they adopted - not adopted), $\mathrm{BH}=$ Base heterogeneity (adopted - had they adopted), TH = Transitory heterogeneity (TT $-\mathrm{TU})$

By embracing the technologies, adopters were able to move from the worse off wealth status (had they not adopted) to the well-endowed category (Table 9). Those who did not adopt are not necessarily worse off for not doing so. They are however almost at the border line between being well off and worse off in terms of the wealth index. Their wealthy status could have improved tremendously had they adopted the soil fertility improving tree technologies. The effect of the technologies in improving farmer welfare was more pronounced for the adopters than the non-adopters (Table 9). This perhaps explains why this group of households adopted the technologies in the first place. Generally, it can be concluded that the technologies are able to improve the wealth status of the adopters.

\section{Conclusions}

Soil fertility improving tree technologies have been promoted as alternatives to the costly inorganic fertilisers among poor resource farmers of Sub Saharan Africa since the late 1980s. There is increasingly evidence that the technologies are not being embraced as expected. This is very surprising given that the majority of small holder farmers cannot afford inorganic or mineral fertilisers. Biophysical research findings point to the fact that these technologies are able to double or more than double the crop yield productivity over the non-use of inputs, a 
practice common among the resource poor farmers. It was therefore pertinent to know whether similar results could be obtained on farmers' fields where the socioeconomic as well as environmental conditions could limit the capacity of the technologies to increase crop productivity hence famer welfare. Findings from 1,231 farming households across six districts of Zambia show that the technologies increases maize productivity. However, the increases are less than those obtained from controlled on-station and field experiments. The increases among the adopters of the technologies were around 18 and $75 \%$ if only observable covariates and non-observable covariates are controlled for, respectively. The predictions among the non-adopters showed that the technologies could barely double the maize crop yields.

The findings implications suggest that on-farm socioeconomic constraints need to be tackled for the technologies to give maximum benefits. Households' availability of labour and sharing of ideas in agricultural groups proved significant in the maize productivity and adoption of soil fertility improving trees models. Soil fertility improving trees that are less labour intensive would stand a higher chance of being adopted by the farming households. Research on agroforestry should therefore be redirected towards the discovery of such labour saving technologies.

The technologies capacity to contribute to wealth creation was also confirmed. Switching to planting soil fertility improving tree technologies in the wealth model was positively affected by access to information and credit, and negatively affected by cropped area. The power of information in the adoption of technologies can not overly be emphasized. Households putting more land into crop production would not leave enough land to use on the soil fertility improving technologies. Access to credit would make resources available to diversify into many farm activities including the planting of tree technologies. Since the Government of Zambia subsidises inputs to most resource poor small scale farmers through the Farmer Input Support Programme (FISP), consideration towards including soil fertility improving tree germplasm in the FISP could be an option. Farmer investment in these technologies could also be enhanced through increased promotion of extension messages on the viability of the technologies to provide both private and societal benefits.

\section{Acknowledgements}

The Research team acknowledges financial support from Michigan State University and Administrative support from the University of Zambia. The team also acknowledges the many data collection assistants and the farmers who participated in the surveys. The support of the Indaba Agricultural Policy Research Institute (IAPRI) is also acknowledged.

\section{References}

Ajayi, O. C., Akinnifesi, F. K., Sileshi, G., Chakeredza, S., \& Matakala, P. (2007). Economic framework for integrating environmental stewardship into food security strategies in low-income countries: case of agroforestry in southern African region. African Journal of Environmental Science and Technology, 1(4), 059-067.

Akinnifesi, F. K., Makumba, W., \& Kwesiga, F. (2006). Sustainable maize production using Gliricidia/maize intercropping in Southern Malawi. Experimental Agriculture, 42, 441-457. https://doi.org/10.1017/S0014479706003814

Antle, J. M., \& Diagana, B. (2003). Creating incentives for the adoption of sustainable agricultural practices in developing countries: the role of soil carbon sequestration. American Journal of Agricultural Economics, 85, 1178-1184. http://dx.doi.org/10.1111/j.0092-5853.2003.00526.x.

Brookhart, M. A., Schneeweiss, S., Rothman, J. K., Glynn, J. R., Avorn, J., \& Sturmer, T. (2006). Variable selection for propensity score models. American Journal of Epidemiology, 163, 12. https://doi.org/10.1093/aje/kwj149

Caliendo, M., \& Kopeinig, S. (2008). Some practical guidance for implementation of propensity score matching. Journal of Economic Surveys, 22(1), 31-72. http://doi.org/10.1111/j.1467-6419.2007.00527.x

Chabala, L. M., Kuntashula, E., Kaluba, P., \& Miyanda, M. (2015). Assessment of maize yield variations due to climatic variables of rainfall and temperature. Journal of Agricultural Science, 7, 11. http://dx.doi.org/10.5539/jas.v7n11p143

Filmer, D., \& Pritchett, R. H. (1998). The effect of household wealth on educational attainment: demographic and health survey evidence. Policy Research Working Paper No. 1980, The World Bank. https://doi.org/10.1596/1813-9450-1980

Kuntashula, E., \& Mungatana, E. (2013). Estimating the causal effect of improved fallows on farmer welfare 
using robust identification strategies in Chongwe - Zambia. Agroforestry Systems, 87, 1229-1246. https://doi.org/10.1007/s10457-013-9632-y

Kuntashula, E., van der Horst, D., \& Vermeylen, S. (2014). A pro-poor biofuel? Household wealth and farmer participation in Jatropha curcas seed production and exchange in Eastern Zambia. Biomass and Bio-energy, 63, 187-197.

Kwesiga, F., \& Coe, R. (1994). The effect of short rotation Sesbania sesban planted fallows on maize yield. Forest Ecology and Management, 64, 199-208. https://doi.org/10.1016/0378-1127 (94)90294-1

Kwesiga, F., Akinnifesi, F. K., Mafongoya, P. L., McDermott, M. H., \& Agumya, A. (2003). Agroforestry research and development in southern Africa during the 1990s: review and challenges ahead. Agroforestry System, 59, 173-186. https://doi.org/10.1023/B:AGFO.0000005222.68054.38

Langyintuo, A. S., \& Mungoma, C. (2008). The effect of household wealth on the adoption of improved maize varieties in Zambia. Food Policy, 33(6), 550-559. https://doi.org/10.1016/j.foodpol.2008.04.002

Langyintuo, A.-S. (2008). Computing household wealth indices using principal components analysis method. CIMMYT Working Paper, Harare, Zimbabwe.

Lokshin, M., \& Sajaia, Z. (2004). Maximum likelihood estimation of endogenous switching regression models. Stata Journal, 4(3), 282-289.

Maddala, G. S., \& Nelson, F. D. (1975). Switching regression models with exogenous and endogenous switching. Proceeding of the American Statistical Association (Business and Economics Section), 423-426.

Mafongoya, P. L., Kuntashula, E., \& Sileshi, G. (2006). 'Managing soil fertility and nutrient cycles through fertiliser trees in Southern Africa' in U. Norman, S.A. Ball, C.M.E Fernandes, H. Herren, O. Husson, C. Palm, J. Pretty, N. Sanginga and J.E. Thies JE (eds.), Biological approaches to sustainable soil systems, Taylor \& Francis Group, Boca Raton, Florida, USA, pp 273-289.

Quinion, A., Chirwa, P. W., Akinnifesi, F. K., \& Ajayi, O. C. (2010). Do agroforestry technologies improve the livelihoods of the resource poor farmers? Evidence from Kasungu and Machinga districts of Malawi. Agroforestry Systems, 80, 457-465. https://doi.org/10.1007/s10457-010-9318-7

Rosenbaum, P. R., \& Rubin, D. B. (1983). The central role of the propensity score in observational studies for causal effects. Biometrika, 70(1), 41-55. https://doi.org/10.2307/2335942

Sileshi, G., Akinnifesi, F. K., Ajayi, O. C., Chakeredza, S., Kaonga, M., \& Matakala, P (2007). Contribution of agroforestry to ecosystem services in the miombo eco-region of eastern and southern African. African Journal of Environmental Science Technology, 1(4), 068-080.

\section{Copyrights}

Copyright for this article is retained by the author(s), with first publication rights granted to the journal.

This is an open-access article distributed under the terms and conditions of the Creative Commons Attribution license (http://creativecommons.org/licenses/by/3.0/). 